\title{
Effects of Chronic Social Stress on Obesity
}

\author{
Karen A. Scott • Susan J. Melhorn • Randall R. Sakai
}

Published online: 11 January 2012

(C) Springer Science+Business Media, LLC 2012

\begin{abstract}
The prevalence of overweight and obesity has markedly increased during the past few decades. Stress has been suggested as one environmental factor that may contribute to the development of obesity. In this review, we discuss the role that exposure to chronic stress may play in the development of obesity, with particular attention to the effects of chronic psychosocial stress. Of particular importance is the effect that social stress has on dietary preference, food consumption, and regional distribution of adipose tissue. We present evidence from human and animal studies that links sympathetic nervous system and hypothalamic-pituitaryadrenal axis hyperactivity with visceral obesity, and that stress tends to alter the pattern of food consumption, and promotes craving of nutrient-dense "comfort foods." Lastly, we discuss the visible burrow system, a model of chronic social stress used in our laboratory to assess the effects of social subordination on behavioral and metabolic profile.
\end{abstract}

\footnotetext{
K. A. Scott $\cdot$ R. R. Sakai $(\bowtie)$

Department of Psychiatry and Behavioral Neurosciences, University of Cincinnati College of Medicine,

2170 East Galbraith Road, E 212,

Cincinnati, OH 45237, USA

e-mail: sakairr@ucmail.uc.edu

K. A. Scott

e-mail: scottk2@mail.uc.edu

S. J. Melhorn

University of Washington, Harborview Medical Center, 925 Ninth Avenue, Box 359780, Seattle, WA 98104, USA

e-mail: smelhorn@u.washington.edu
}

Keywords Social stress · Corticosterone - Cortisol · Sympathetic nervous system · HPA · Hypothalamic-pituitary adrenal axis · Dominance $\cdot$ Subordination $\cdot$ Catecholamines . Obesity $\cdot$ Animal models

\section{Introduction}

The prevalence of overweight and obesity has dramatically risen over the past few decades. Although the rate of increase has begun to slow (at least temporarily) in the United States, approximately two thirds of the population is overweight, and nearly one third is obese [1]. Initially thought to be a problem of a small number of wealthy nations, it is now clearly a global issue [2]. Although overeating and sedentary lifestyle are the most frequently cited suspects, there are likely many other contributors to the surge in obesity and obesity-related illness, including cultural, industrial, and genetic factors [3, 4]. The "thrifty gene" hypothesis put forth by James Neel would suggest that from an evolutionary standpoint, the genetic propensity to gain weight and adiposity was adaptive - in times when food was scarce and energy demands great, it was important for the body to use nutrients efficiently and to store any excess energy for future states of negative energy balance [5]. However, John Speakman [6] hypothesizes that genes promoting obesity have always been maladaptive. He proposes that our ancestors lived in an environment that would weed out disadvantageous genes at either end of the metabolic spectrum. He notes that nearly $10 \%$ of fossilized hominids from the Pliocene era show evidence of predation [6], and that genes promoting obesity would also be selected against, as carrying excess weight would impair the ability to escape. Fol- 
lowing the development of tools, the use of fire, and more organized social structures, humans were less vulnerable to predation. Therefore, he has proposed that this "release from predation" has allowed maladaptive genes promoting obesity to be passed down through generations in evolutionary drift [7].

Regardless of whether genes promoting obesity were ever adaptive or maladaptive, both hypotheses highlight the importance of gene $\mathrm{x}$ environment interactions. The disparity between the environment and lifestyle of our ancestors and that of today clearly plays a role in the development of obesity $[5,8,9]$. Other factors likely confer resilience or vulnerability to metabolic dysfunction. Stress has long been associated with changes in dietary preference, food intake, weight gain, and fat accrual, although specific mechanisms are less well understood. Importantly, psychological stress is linked to visceral deposition of fat, which is associated with greater health risks [10-13]. In this review we outline the stress response and how its derangement can negatively affect metabolic health through changes in feeding behavior and metabolic function. We review evidence from humans and animal models, with a focus on chronic social stress studies ongoing in our laboratory.

\section{The Stress Response in Health}

Stress is generally defined as a real or perceived threat to homeostasis [14]. Although often thought of as a negative thing, the stress response is critical to survival, as its function is to help the organism adapt to challenge and maintain homeostasis [15]. When one experiences acute stress (eg, a threat from a predator), the sympathetic branch of the autonomic nervous system (ANS) is rapidly activated, followed by the hypothalamic-pituitary-adrenal (HPA) axis. The ANS governs visceral functions such as respiration, heart rate, maintenance of blood pressure, hormone release, and digestion. Acute activation of the sympathetic nervous system (SNS) following stress exposure is often referred to as the "fight or flight" response. The SNS increases respiration, blood pressure, and heart rate, and activates catabolic pathways. Catecholamines bind to $\beta$ - adrenergic receptors of adipocytes, inducing lipolysis via hormone-sensitive lipase. This frees nonesterified fatty acids from adipocytes and releases them into the circulation. Glycogen is hydrolyzed and gluconeogenesis is stimulated to provide glucose to tissues requiring large amounts of energy (primarily the brain, and skeletal and cardiac muscle) necessary to cope with the threat to homeostasis [16]. SNS activation inhibits the effects of insulin, and functions not necessary for immediate survival (eg, digestion, growth, and reproduction) are suppressed during this period.

Stress also triggers the HPA axis through activation of the parvocellular cells of the paraventricular nucleus of the hypothalamus (PVN). This results in the release of corticotropinreleasing hormone $(\mathrm{CRH})$ and arginine vasopressin into the hypothalamo-pituitary portal circulation. $\mathrm{CRH}$ stimulates the synthesis and release of adrenocorticotropic hormone (ACTH) from the anterior pituitary, which binds to receptors on the adrenal cortex, inducing the release of glucocorticoids from the zona fasciculata (primarily cortisol in humans and corticosterone in rats and mice), the end product of the HPA axis [17, 18]. Glucocorticoids bind to corticosteroid receptors, glucocorticoid (GR) and mineralocorticoid, which are, for the most part, intracellular receptors. Glucocorticoids are lipophilic and can therefore pass through cell membranes to bind with GR within the cytosol, forming a complex with other proteins. After binding, GRs translocate to the nucleus of the cell, where they act as transcription factors, binding to positive or negative glucocorticoid response elements to activate or repress gene expression. Similar to catecholamines, glucocorticoids increase lipolysis and gluconeogenesis and antagonize the anabolic actions of insulin by inhibiting both its release from pancreatic $\beta$ cells, as well as its signaling abilities [19], allowing glucose, fatty acids, and amino acids to be shunted to the tissues that need them most.

In healthy individuals the stress response is short lived. Activation of the SNS is rapidly counterbalanced by the parasympathetic ("rest and digest") branch of the ANS. The HPA response is terminated via negative feedback loops; glucocorticoids act on receptors at the level of the PVN and pituitary to inhibit the production and release of $\mathrm{CRH}$ and ACTH. Indirect negative feedback from limbic structures such as the medial prefrontal cortex and hippocampus also contributes to termination of the HPA axis response. Although the stress response is necessary for survival and adaptation, pathology can arise when it is prolonged. In vulnerable individuals, exposure to chronic stress can adversely affect numerous aspects of health $[8,9,15]$.

\section{How Can Social Stress Contribute to Obesity?}

It seems counterintuitive that prolonging the stress response could result in obesity; mounting a stress response is an energetically costly activity and it serves to mobilize energy stores for immediate use. This is true for acute stress, but periods of chronic stress exposure promote acquisition and/ or redistribution of energy stores. Although certainly a subjective measure, most people consider themselves "stressed," and most frequently report that the source is social in nature. Common psychosocial stressors include low socioeconomic status, personal conflicts with friends and family, stressful work environments, lack of adequate social support, poor self-esteem, trying to balance home and work life, or caring for a sick loved one [8, 20-22]. Because these are chronic types of stressors, they contribute to increased weight gain and visceral adiposity. Socioeconomic status is strongly related with disease and mortality, and has been dubbed "the status syndrome" by Marmot [23]. In the United States, poor citizens 
have significantly poorer health than the rich. Lack of, or inadequate, health insurance and access to health care certainly contributes to the particularly wide gap among Americans, but disparity is still observed in countries with universal health care. The gap is observed despite accounting for lifestyle differences, and Marmot [23] asserts that this is likely due to the psychological effects of low status - one's relative status and perception of control and integration within society. Although social hierarchies are inherent in human society, the magnitude of the health disparity between the affluent and poor may be ameliorated by addressing inequalities, improving access to health care and supportive resources, providing a greater sense of control, and participation with society [24].

In addition to the metabolic effects, stress can also affect appetite and influence dietary preference. These effects are not always consistent-many people report that they tend to gain weight when they are stressed, whereas others report loss of appetite. Differences may reflect the type of stressor, its duration or severity, genetic predisposition, and learned coping style $[25,26]$. Another factor is pre-existing weight: men and women that are overweight or at the upper limits of "normal" weight are more likely to gain weight in response to stress than those that are of lower weight. It is believed that elevated insulin levels observed in heavier individuals are responsible for greater weight gain in response to stress $[27 \cdot, 28]$. Many people who increase food intake in response to stress report craving foods high in fats and sugar. This "comfort food" effect is thought of as non-homeostatic feeding and is proposed to activate brain reward systems and dampen stress responses. For some obese patients, overconsumption of palatable foods is thought of as a form of addiction. Imaging studies have revealed dysregulation of dopaminergic reward circuitry, similar to that observed in drug addiction [26, 29•]. Chronic social stress, access to highly palatable, energy-dense foods, and little need for physical activity set the stage for the development of overweight and obesity.

\section{Chronic Activation of the Stress Response}

\section{Effects of Chronic Sympathetic Activation on Metabolism}

Chronic SNS activation has generally been associated with the development of obesity [30-32]. If SNS activation increases metabolism, mobilization of energy stores, energy expenditure, and thermogenesis, it would seem to make sense that obesity would be associated with lowered SNS activity [16]. Differences are most likely a consequence of the method by and time of assessment. Most studies agree that basal SNS activity is elevated in those with metabolic disorders. However, there is some disagreement about what happens in response to challenge, such as insulin administration or cold stress $[16,33]$. Studies suggest that although basal SNS activity may be chronically elevated, the response to stress is blunted. It is hypothesized that these high levels of basal catecholamines induce downregulation or desensitization of adrenergic receptors in adipose tissue. This, in turn, inhibits lipolysis upon activation of the SNS, and leads to insulin resistance. Spraul et al. [31] found that increased SNS activity, as measured by muscle sympathetic nerve activity, was directly related to body composition. Others have demonstrated that men with low job status have lower heart rate variability, indicating enhanced sympathetic activity [34]. But is SNS hyperactivity a cause or consequence of obesity? Recent studies have indicated that heightened sympathetic activity may precede overweight and obesity in individuals. Elevated resting and ambulatory heart rate have been directly related to overweight and obesity in follow-up examinations of hypertensive patients [35]. Similarly, a prospective study of healthy, nonobese males found that those with elevated plasma norepinephrine gained more weight over a 5-year period [36].

\section{HPA Axis Hyperactivity}

Chronic activation of the HPA axis has been associated with numerous pathologies, including metabolic disorders. In fact, many of the symptoms of the metabolic syndrome are shared with those of Cushing's syndrome, caused by hypercortisolism. These include the preferential deposition of adipose tissue in the midsection, hypertension, dyslipidemia, and insulin resistance [37-39]. Although an acute stress response promotes mobilization of energy stores for use, chronic glucocorticoid exposure has the opposite effect, promoting energy storage as fat, and preferentially within the abdomen. For example, chronic variable stress or administration of exogenous corticosterone increases body weight, mesenteric fat pad weight, leptin levels, and adipocyte size of rodents $[13,40]$. The overall effects of glucocorticoid exposure differ by tissue type. Chronic glucocorticoid exposure increases the expression and activity of lipoprotein lipase within adipose tissue depots, facilitating fat storage, and this predominates within visceral adipose tissue since visceral depots express more GR than subcutaneous depots. The stromal vascular cells of visceral adipose express higher levels of $11 \beta$-hydroxysteroid dehydrogenase (11 $\beta$-HSD-1), an enzyme that regenerates glucocorticoids from their inactive metabolites, further augmenting local glucocorticoid action in abdominal fat [41, 42].

\section{Does Social Stress Cause Human Obesity?}

Numerous epidemiologic studies have linked social stress with obesity and metabolic disorders. However, it is difficult to determine whether stress contributes to the development of metabolic dysfunction or is a result of metabolic 
dysfunction itself. Because of the difficulties associated with long-term studies, many rely on measures taken over a short period of time, metabolic response to acute stressors, or retrospective studies. However, some recent studies have looked at psychosocial factors and metabolic function over longer periods of time. Beginning with baseline measures taken in the mid- to late $1980 \mathrm{~s}$, health data have been regularly collected from a large group of UK civil servants, in what is referred to as the Whitehall II Studies. One recent follow-up found that men and women who reported longterm conflicts within, or lack of support from, their closest relationships were more likely to have had an increase in waist circumference and body mass index (BMI) over the study period [43]. Others studying the Whitehall II cohort have found associations between chronic stress and other factors associated with metabolic syndrome, such as elevated basal sympathetic activity or prolonged sympathetic response to stress [21, 34]. Similarly, a recent Finnish study conducted over a 6-year period found that adults selfreporting psychological distress had a significantly higher likelihood of developing the metabolic syndrome by study end [44].

A particularly troubling issue is the number of children and adolescents who are classified as overweight or obese. Recent estimates indicate that approximately $17 \%$ of children in the United States are obese [45]. It is already well established that childhood obesity often persists into adulthood, and recent studies suggest that childhood overweight and obesity are associated not only with poor health in adulthood, but shortened lifespan [46]. As in adults, the nutritional and social environment likely plays a large role in pediatric obesity. Although we are all exposed to social stressors, adolescents may be particularly vulnerable to their deleterious effects on health [47]. Adolescence is a period of development associated with the desire for more independence from family, which can lead to conflict. Desire for acceptance from peers can lead to significant social pressure. It is also a period in which the brain is still developing and attitudes about food and coping behaviors are learned. Although the overall rise in childhood obesity has slowed, it has not for those from disadvantaged backgrounds [48]. Low income has been associated with higher risk of childhood overweight and obesity in several studies [47, 49-52]. Stamatakis et al. [53・•] contend that there is in fact a growing divide between the upper class and those with a lower socioeconomic status.

\section{Animal Models of Stress}

Because of obvious technical and ethical constraints, there are limitations to stress studies in humans. Clearly, it is not ethical to purposefully subject humans to chronic social stress. It takes decades to conduct prospective studies of long-term social stress on human health. For these reasons, animal models can help to elucidate mechanisms by which stress impacts physiology. It is of great importance to thoughtfully consider the model that is used; it should be ethologically relevant to the animal, and should also translate to the human condition. Although in the past it was assumed that all stressors were generally the same, we now realize that psychological and physiologic stressors can utilize very different neural circuitry $[54,55]$. Therefore, studies of social species in a social environment may be most useful in modeling the human condition. Numerous species have been used to study stress effects, including nonhuman primates, rodents, and zebrafish.

Nonhuman primates have provided invaluable insight into the effects of social stress; since they are most closely related to humans, they share many physiologic and neuroanatomical features. Female nonhuman primates have a reproductive cycle that more closely resembles that of humans, and many nonhuman primate species also form dominance hierarchies, allowing for the investigation of sexually dimorphic effects of social subordination. Nonhuman primates also share many of the same genetic polymorphisms as humans that have been associated with vulnerability or resilience to disease. Their average lifespan is considerably shorter than humans, but much longer than those of rodents, which makes them ideal for longitudinal studies. Although less closely related to humans than nonhuman primates, rats and mice still share many similarities, which are supported by a rich literature of behavior and comparative anatomy and physiology. Because of their size and shorter lifespan, they require far fewer resources (time, space, and economic) and can provide valuable information over a shorter period of time than nonhuman primates. A particular strength of rodent models is the wide variety of strains available. Rats and mice have been selectively bred for particular traits such as coping style, susceptibility to disease, and diet-induced obesity [56-58, 59•, 60]. Additionally, the ability to look at the effects of down- or upregulation of gene expression via spontaneous mutations, transgenics, and the use of viral vectors yields invaluable information on genetic vulnerability or resilience to disease [61-65]. Zebrafish (Danio rerio) may also help us to elucidate the genetic and epigenetic mechanisms that underpin behavioral or coping strategies. These social fish have a well-documented behavioral repertoire and share similar neuroendocrine and neurotransmitter systems and basic neuroanatomy to those in humans, nonhuman primates, and rodents. A particular strength of the zebrafish is that its genome has been fully sequenced, and a number of mutant models are available for study [66]. For instance, zebrafish with a mutation of the fibroblast growth factor receptor 1a ( fgfrla) gene engage in more exploration of a novel environment, spend more time in proximity to a novel object, 
and exhibit more aggressive behaviors toward a "conspecific" (reaction to its own reflection in a mirror). This single mutation appears to influence the temperament or coping style of the zebrafish [67]. It appears that the gene affects behavior through its influence on histamine expression, which is reduced in the fgfrla mutant fish. Restoring histamine to normal levels resulted in behavior similar to that of wild-type zebrafish. It is also possible to study the effects of social stress in zebrafish, as dominance is established when males are pairhoused [68].

Social stress in animals affects food intake, food preference, and body composition. Subordinate (SUB) nonhuman primates exhibit behavioral and physiologic symptoms of stress, including depressive-like behaviors and increased HPA axis and SNS activity. Sexually dimorphic effects on fat deposition exist in both humans and nonhuman primates, and can therefore facilitate study into the mechanisms by which males are more vulnerable to developing visceral obesity. In male cynomolgus macaques, social instability (generated by frequently changing the composition of social groups) results in increased coronary artery atherosclerosis and deposition of abdominal adipose tissue [69, 70]. Males with the greatest heart rate responses to stressors (a measure of sympathetic activation) also have the most severe atherosclerosis [69]. SUB female rhesus macaques consume more calories than dominant (DOM) females when provided with a standard diet. When provided with a choice between the standard diet and a highly palatable high-calorie diet, both DOM and SUB females preferred the high-calorie diet, but the SUB females continue to consume more than the DOM females. When provided with a moderate-fat diet, SUB female cynomolgus monkeys are more likely to centralize fat stores than DOM females [71, 72]. Similarly, SUB male mice consume more high-fat diet than DOM males, and have improved caloric efficiency, leading to weight gain and elevated plasma glucose and free fatty acids.

Access to and consumption of palatable food and drink appears to ameliorate or prevent some of the behavioral and physiologic effects of stress. In the previously mentioned study, consumption of the high-calorie diet was associated with a decrease in aggression and anxiety-related behaviors in SUB female cynomolgus monkeys [73]. Male rats provided daily access to a small amount of sweetened solution have a blunted HPA axis response to acute stressors such as restraint $\left[74,75^{\bullet}\right]$.

\section{The Visible Burrow System}

Our laboratory examines the effects of chronic social stress on metabolism using the visible burrow system (VBS), which is used to create a semi-natural, ethologically relevant habitat for socially housed rats. It consists of a series of tunnels and chambers, meant to simulate burrows formed by wild rats, and an open surface area exposed to a 12:12 light cycle (Fig. 1). When males and females are housed within this system, males form a dominance hierarchy. SUB males exhibit signs of social stress including lower testosterone, elevated corticosterone, adrenal hypertrophy, thymic involution, hypophagia, and weight loss over the 2-week housing period [76-79]. At the end of this period, both DOM and SUB males lose fat mass, but SUB males lose a greater proportion of subcutaneous to visceral adipose tissue than DOM males. SUB males also lose a significant amount of lean tissue. Upon removal and a 3-week recovery period of single housing, SUB males are hyperphagic and accrue a significant amount of adipose tissue, preferentially stored in visceral depots [77, 80, 81]. This suggests increased visceral adiposity, despite the finding that the body weight does not return to that of DOMs and CONs (controls; singly housed males) during a 3-week recovery period. This is similar to a recent cross-sectional study of men that found that although self-reported stress scores did not correlate with BMI, they were directly related to body composition [82]. In the VBS, body compositional effects are enhanced by multiple cycles through VBS and recovery [81, 83•]. On the surface, the VBS model differs from animal and human models in that the most socially stressed animals lose weight. However, this may be an effect of the severity of the social stress within the burrow. The release and recovery from this stress is likely responsible for the rapid recovery of weight and preferential deposition of visceral fat. When SUBs come out of the VBS, they have elevated glucocorticoids, low testosterone, and upregulation of orexigenic hypothalamic neuropeptides, which most likely contributes to this phenotype. Much of our recent research has focused on the mechanisms by which this preferential fat gain occurs. Two recent studies have focused on the roles of pattern of food ingestion and nutrient trafficking during and following subordination stress.

\section{Stress-Induced Changes in Feeding Behavior}

One area of interest is how feeding patterns are altered during VBS housing and recovery. Others have demonstrated that the manner in which one consumes food can affect weight gained and/or body composition, even when the total caloric intake is the same [84-86]. Monitoring food intake of group housed animals is not an easy task; continuous video recording allowed us to determine when each rat was at a feeder, but it was not suitable for studying how much food was consumed or the microstructure of meals. In collaboration with AccuScan Instruments (Columbus, $\mathrm{OH}$ ) and the University of Cincinnati (UC) Biomedical Engineering Department, we have modified a meal pattern system (Dietmax ID, AccuScan Instruments) with which to study the meal patterns of males within the VBS (Fig. 1). Prior to 
Fig. 1 Illustrates the visible burrow system with food intake monitoring equipment

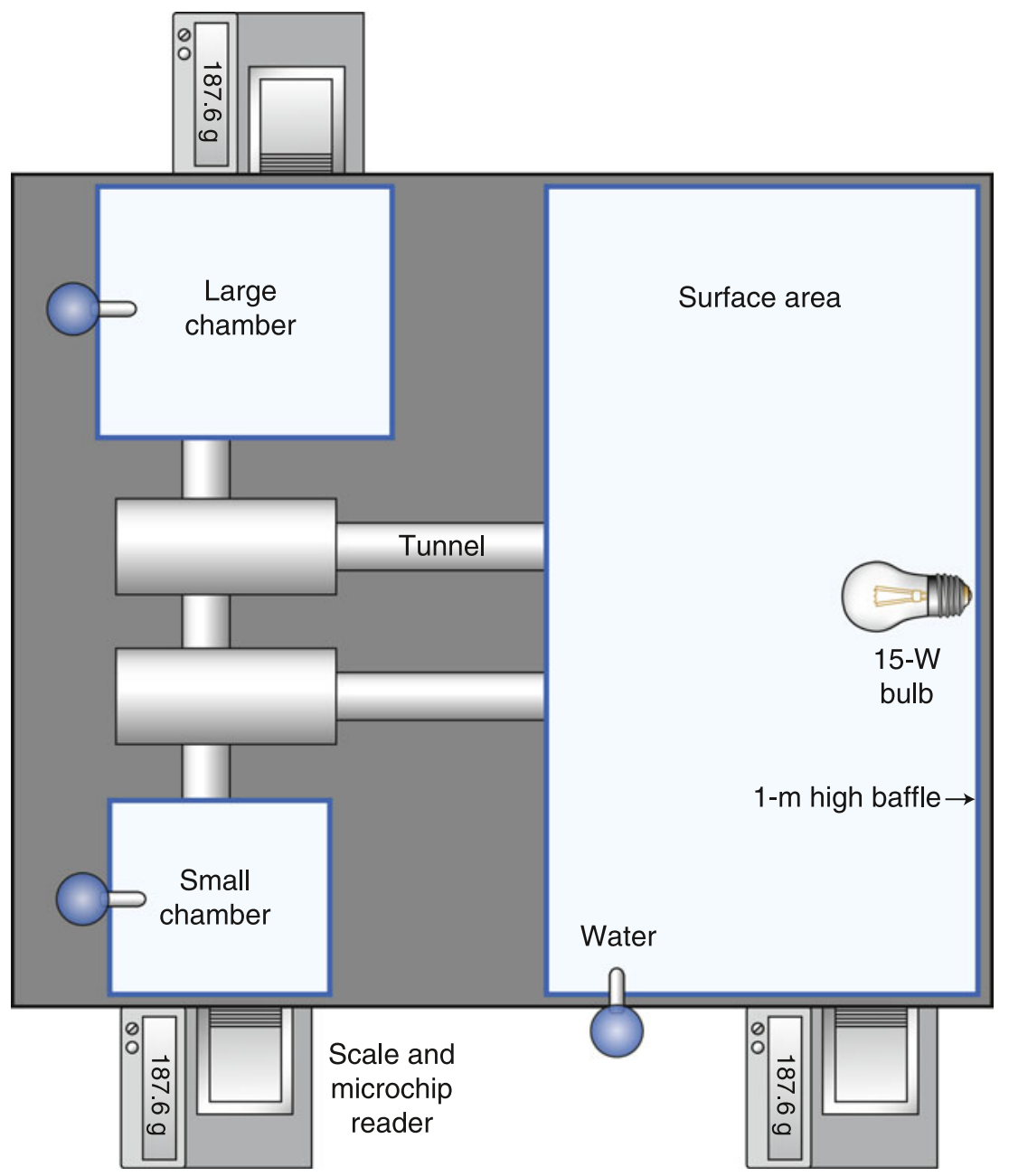

the study, each male is implanted with a small microchip that can be read by scanners located above feeding cups within the VBS. The food cups sit upon scales connected to an analyzer which records, with a timestamp, all changes in cup weight (Dietmax ID System). This allows us to determine where and when each rat fed, in addition to the amount of food consumed. The UC Biomedical Engineering Department has developed a program in which these data can be analyzed to determine meal patterns for each animal; the number of meals taken, size of individual meals, duration of meals, and intermeal interval, a measure of time taken between meals. A more thorough explanation of the meal pattern equipment can be found in a recently published study by Melhorn et al. [83•]. The food intake of DOMs and SUBs decreases significantly during the first day of VBS housing, as the dominance hierarchy is established. However, DOMs rapidly return to their basal food intakes. The reduction in food intake of SUBs persists through the duration of VBS housing, and occurs through a reduction in both the size and number of meals. This reduction occurs voluntarily; food is readily available in each chamber and the open surface area. The temporal pattern of food intake of SUBs is markedly altered. Whereas DOMs and CONs consume the bulk of their meals during the dark period (since rats are a nocturnal species), SUBs take meals throughout the 24-hour period, including many during the light period [83•].

When SUBs are removed from the VBS and allowed to recover in individual cages, they are hypercorticosteronemic and hyperphagic. SUBs consume fewer meals, but the meal size is significantly greater than $\mathrm{CONs}$, a pattern associated with preferential adipose gain, as noted previously. They also continue to consume more meals during the light period during the first week of recovery, which may further contribute to weight gain during recovery, as disrupted sleep or reverse feeding represent additional stressors associated with sympathoadrenal hyperactivity-altered metabolic profile and obesity [40, 87, 88]. Although DOMs regain adipose tissue during a 3-week recovery period, SUBs have a much more exaggerated gain in adiposity, which is most pronounced during the first week of recovery [83•].

\section{Stress-Induced Changes in Glucose Trafficking}

Glucose trafficking may play an important role in body composition changes during and in recovery from social 
stress. Epidemiologic studies have found that psychosocial stressors correlate to poor glycemic control [82, 89]. We have recently begun to examine the effects of social stress on glucose transporter 4 (GLUT4) expression of SUB rats during VBS housing and following a recovery period. GLUT4 is an insulin-dependent glucose transporter located in adipose tissue, muscle, and brain. Insulin stimulates translocation of GLUT4 from vesicles within the cytosol to the plasma membrane, and enabling glucose uptake into the cell. Chronic activation of the stress response is associated with insulin resistance, impairing GLUT4-mediated glucose uptake. GLUT4 expression is highly regulated by glucocorticoids and transcription can be directly modulated by local glucocorticoid levels. Our preliminary data indicate that DOM males have an increased ratio of plasma membrane (translocated, active) to whole membrane (cytosolic) GLUT4 protein in skeletal muscle, compared with CONs and SUBs, suggesting a mechanism by which DOMs preferentially gain lean tissue in recovery. We find that SUBs are not glucose intolerant at the end of VBS housing, despite elevated corticosterone levels. This is most likely due to increased physical activity within the burrow, which has been shown to increase muscle GLUT4 translocation and insulin sensitivity; offsetting the suppressive effects of elevated glucocorticoids [90]. We are currently looking at GLUT4 expression in different adipose depots of DOMs, CONs, and SUBs. Although many studies report that elevations in glucocorticoids inhibit insulin sensitivity in both adipose tissue and skeletal muscle, others have found that elevations can enhance insulin sensitivity in human adipocytes [91]. Increased adipose gain in SUBs during recovery suggests that there may be an upregulation in adipose GLUT4 expression, or an enhancement of translocation from intracellular stores to the plasma membrane, augmenting glucose uptake.

\section{Conclusions}

Obesity and its associated health risks have risen dramatically in the past few decades. Sedentary lifestyle and easy accessibility to highly palatable nutrient-dense foods creates an environment that promotes overweight and obesity. Chronic social stress, often arising from poor interpersonal relationships, job or unemployment stress, poor self-esteem, and low socioeconomic status has been associated with obesity and its associated illnesses. Chronic activation of the SNS and HPA axis contribute to a anabolic state that promotes fat storage within visceral depots, which increases the risk of dyslipidemia, type 2 diabetes, cardiovascular disease, and other facets of the metabolic syndrome. Stress can also enhance weight gain and fat deposition through changes in feeding behavior. Chronic stress is known to alter the pattern of food intake, dietary preference, and the rewarding properties of foods.

Animal models, such as colony housing of rodents and nonhuman primates have provided invaluable insight into the mechanisms by which obesity may arise from social stress exposure. Although the ideal model to study effects of stress on humans is, of course, humans, ethical and logistical issues often preclude such studies. Human responses to social stress also vary widely among individuals, and it is impossible to completely control for aspects of individual personal experience. For these reasons, ethologically relevant animal models of social stress can fill an important void in understanding how social stress may contribute to obesity.

Of course, there are some aspects that cannot be modeled in animals. Some emotions experienced in response to social stress such as shame, guilt, and self-consciousness are considered by most to be unique to humans. Therefore, it is important to consider animal studies as a complement to studies in humans that may provide insight into the neural mechanisms and genetic factors that underlie stressassociated illness. This in turn may facilitate the development of interventions that may prevent and/or treat stressrelated metabolic dysfunction.

Disclosure Conflicts of interest: K.A. Scott: is supported by National Institutes of Health (NIH) grant MH088230; S.J. Melhorn: none; R.R. Sakai: has been a board member for Physiology \& Behavior; has been a grant reviewer for the National Science Foundation; is employed by the University of Cincinnati; is supported by NIH grant DK068273, and a grant from the Department of Defense; and has received travel/accommodations expenses covered or reimbursed from the National Science Foundation.

\section{References}

Papers of particular interest, published recently, have been highlighted as:

- Of importance

-. Of major importance

1. Flegal KM, Carroll MD, Ogden CL, Curtin LR. Prevalence and trends in obesity among US adults, 1999-2008. JAMA. 2010;303 (3):235-41.

2. Selassie M, Sinha AC. The epidemiology and aetiology of obesity: a global challenge. Best Pract Res Clin Anaesthesiol. 2011;25 (1):1-9.

3. Keith SW, Redden DT, Katzmarzyk PT, et al. Putative contributors to the secular increase in obesity: exploring the roads less traveled. Int J Obes (Lond). 2006;30(11):1585-94.

4. McAllister EJ, Dhurandhar NV, Keith SW, et al. Ten putative contributors to the obesity epidemic. Crit Rev Food Sci Nutr. 2009;49(10):868-913.

5. Siervo M, Wells JC, Cizza G. The contribution of psychosocial stress to the obesity epidemic: an evolutionary approach. Horm Metab Res. 2009;41(4):261-70. 
6. Speakman JR. A nonadaptive scenario explaining the genetic predisposition to obesity: the "predation release" hypothesis. Cell Metab. 2007;6(1):5-12.

7. Speakman JR. Thrifty genes for obesity, an attractive but flawed idea, and an alternative perspective: the 'drifty gene' hypothesis. Int J Obes (Lond). 2008;32(11):1611-7.

8. McEwen BS, Gianaros PJ. Central role of the brain in stress and adaptation: links to socioeconomic status, health, and disease. Ann N Y Acad Sci. 2010;1186:190-222.

9. McEwen BS, Stellar E. Stress and the individual. Mechanisms leading to disease. Arch Intern Med. 1993;153(18):2093-101.

10. Bjorntorp P. Adipose tissue distribution and function. Int J Obes. 1991;15 Suppl 2:67-81.

11. Bjorntorp P. The regulation of adipose tissue distribution in humans. Int J Obes Relat Metab Disord. 1996;20(4):291-302.

12. Chrousos GP. The role of stress and the hypothalamicpituitary-adrenal axis in the pathogenesis of the metabolic syndrome: neuro-endocrine and target tissue-related causes. Int J Obes Relat Metab Disord. 2000;24 Suppl 2:S50-5.

13. Rebuffe-Scrive M, Walsh UA, McEwen B, Rodin J. Effect of chronic stress and exogenous glucocorticoids on regional fat distribution and metabolism. Physiol Behav. 1992;52(3):583-90.

14. Goldstein DS, Kopin IJ. Evolution of concepts of stress. Stress. 2007;10(2):109-20.

15. McEwen BS. Protective and damaging effects of stress mediators. N Engl J Med. 1998;338(3):171-9.

16. Lambert GW, Straznicky NE, Lambert EA, Dixon JB, Schlaich MP. Sympathetic nervous activation in obesity and the metabolic syndrome-causes, consequences and therapeutic implications. Pharmacol Ther. 2010;126(2):159-72.

17. de Kloet ER, Joels M, Holsboer F. Stress and the brain: from adaptation to disease. Nat Rev Neurosci. 2005;6(6):463-75.

18. Herman JP, Cullinan WE. Neurocircuitry of stress: central control of the hypothalamo-pituitary-adrenocortical axis. Trends Neurosci. 1997;20(2):78-84.

19. Lundgren M, Buren J, Ruge T, Myrnas T, Eriksson JW. Glucocorticoids down-regulate glucose uptake capacity and insulin-signaling proteins in omental but not subcutaneous human adipocytes. J Clin Endocrinol Metab. 2004;89(6):2989-97.

20. Cohen S. Keynote Presentation at the Eight International Congress of Behavioral Medicine: the Pittsburgh common cold studies: psychosocial predictors of susceptibility to respiratory infectious illness. Int J Behav Med. 2005;12(3):123-31.

21. Steptoe A, Feldman PJ, Kunz S, Owen N, Willemsen G, Marmot M. Stress responsivity and socioeconomic status: a mechanism for increased cardiovascular disease risk? Eur Heart J. 2002;23 (22):1757-63.

22. Wang JL. Perceived work stress, imbalance between work and family/personal lives, and mental disorders. Soc Psychiatry Psychiatr Epidemiol. 2006;41(7):541-8.

23. Marmot MG. Status syndrome: a challenge to medicine. Jama. 2006;295(11):1304-7.

24. Matthews KA, Gallo LC, Taylor SE: Are psychosocial factors mediators of socioeconomic status and health connections? A progress report and blueprint for the future. Ann N Y Acad Sci, 1186:146-173.

25. Pecoraro N, Reyes F, Gomez F, Bhargava A, Dallman MF. Chronic stress promotes palatable feeding, which reduces signs of stress: feedforward and feedback effects of chronic stress. Endocrinology. 2004;145(8):3754-62.

26. Adam TC, Epel ES. Stress, eating and the reward system. Physiol Behav. 2007;91(4):449-58.

27. Dallman MF: Stress-induced obesity and the emotional nervous system. Trends Endocrinol Metab 2009, 21(3):159-165. This is a review of the comfort food hypothesis and how stress can influence food intake and weight gain.
28. Block JP, He Y, Zaslavsky AM, Ding L, Ayanian JZ. Psychosocial stress and change in weight among US adults. Am J Epidemiol. 2009;170(2):181-92.

29. - Volkow ND, Wang GJ, Baler RD: Reward, dopamine and the control of food intake: implications for obesity. Trends Cogn Sci 2011, 15(1):37-46. This outlines how consumption of palatable foods activates reward pathways, and how obesity may relate to addiction.

30. Ravussin E, Tataranni PA. The role of altered sympathetic nervous system activity in the pathogenesis of obesity. Proc Nutr Soc. 1996;55(3):793-802.

31. Spraul M, Anderson EA, Bogardus C, Ravussin E. Muscle sympathetic nerve activity in response to glucose ingestion Impact of plasma insulin and body fat. Diabetes. 1994;43 (2):191-6.

32. Lambert EA, Lambert GW. Stress and its role in sympathetic nervous system activation in hypertension and the metabolic syndrome. Curr Hypertens Rep. 2011;13(3):244-8.

33. Greenfield JR, Campbell LV. Role of the autonomic nervous system and neuropeptides in the development of obesity in humans: targets for therapy? Curr Pharm Des. 2008;14(18):1815-20.

34. Brunner EJ, Hemingway H, Walker BR, et al. Adrenocortical, autonomic, and inflammatory causes of the metabolic syndrome: nested case-control study. Circulation. 2002;106 (21):2659-65.

35. Palatini P, Mos L, Santonastaso M, et al. Resting heart rate as a predictor of body weight gain in the early stage of hypertension. Obesity (Silver Spring). 2011;19(3):618-23.

36. Masuo K, Kawaguchi H, Mikami H, Ogihara T, Tuck ML. Serum uric acid and plasma norepinephrine concentrations predict subsequent weight gain and blood pressure elevation. Hypertension. 2003;42 (4):474-80.

37. Rosmond R. Role of stress in the pathogenesis of the metabolic syndrome. Psychoneuroendocrinology. 2005;30(1):1-10.

38. Bjorntorp P. Do stress reactions cause abdominal obesity and comorbidities? Obes Rev. 2001;2(2):73-86.

39. Macfarlane DP, Forbes S, Walker BR. Glucocorticoids and fatty acid metabolism in humans: fuelling fat redistribution in the metabolic syndrome. J Endocrinol. 2008;197(2):189-204.

40. Karatsoreos IN, Bhagat SM, Bowles NP, Weil ZM, Pfaff DW, McEwen BS. Endocrine and physiological changes in response to chronic corticosterone: a potential model of the metabolic syndrome in mouse. Endocrinology. 2010;151(5):2117-27.

41. Kershaw EE, Flier JS. Adipose tissue as an endocrine organ. J Clin Endocrinol Metab. 2004;89(6):2548-56.

42. Nieuwenhuizen AG, Rutters F. The hypothalamic-pituitaryadrenal-axis in the regulation of energy balance. Physiol Behav. 2008;94(2):169-77.

43. Kouvonen A, Stafford M, De Vogli R, et al. Negative aspects of close relationships as a predictor of increased body mass index and waist circumference: the Whitehall II study. Am J Public Health. 2011;101(8):1474-80.

44. Puustinen PJ, Koponen H, Kautiainen H, Mantyselka P, Vanhala M. Psychological distress predicts the development of the metabolic syndrome: a prospective population-based study. Psychosom Med. 2011;73(2):158-65.

45. Lee JM, Lee H. Obesity reduction within a generation: the dual roles of prevention and treatment. Obesity (Silver Spring). 2011;19 (10):2107-10.

46. Reilly JJ, Kelly J. Long-term impact of overweight and obesity in childhood and adolescence on morbidity and premature mortality in adulthood: systematic review. Int J Obes (Lond). 2011;35 (7):891-8.

47. Gundersen C, Mahatmya D, Garasky S, Lohman B. Linking psychosocial stressors and childhood obesity. Obes Rev. 2010;12(5): e54-63. 
48. Olds T, Maher C, Zumin S, et al. Evidence that the prevalence of childhood overweight is plateauing: data from nine countries. Int $\mathrm{J}$ Pediatr Obes. 2011;6(5-6):342-60.

49. O'Dea JA, Nguyen Hoang TD, Dibley MJ: Plateau in obesity and overweight in a cross sectional study of low, middle and high socioeconomic status schoolchildren between 2004 and 2009. Int J Public Health 2011.

50. Lohman BJ, Stewart S, Gundersen C, Garasky S, Eisenmann JC. Adolescent overweight and obesity: links to food insecurity and individual, maternal, and family stressors. J Adolesc Health. 2009;45(3):230-7.

51. Fontaine KR, Robertson HT, Holst C, Desmond R, Stunkard AJ, Sorensen TIA: Is socioeconomic status of the rearing environment causally related to obesity in the offspring. PloS One 2011, In press.

52. Ludwig J, Sanbonmatsu L, Gennetian L, et al. Neighborhoods, obesity, and diabetes-a randomized social experiment. N Engl J Med. 2011;365(16):1509-19.

53. • Stamatakis E, Wardle J, Cole TJ: Childhood obesity and overweight prevalence trends in England: evidence for growing socioeconomic disparities. Int J Obes (Lond) 2010, 34(1):41-47. This highlights the impact that low socioeconomic status plays in vulnerability to develop overweight and obesity.

54. Pacak K, Palkovits M. Stressor specificity of central neuroendocrine responses: implications for stress-related disorders. Endocr Rev. 2001;22(4):502-48.

55. Pacak K, Palkovits M, Kvetnansky R, Yadid G, Kopin IJ, Goldstein DS. Effects of various stressors on in vivo norepinephrine release in the hypothalamic paraventricular nucleus and on the pituitaryadrenocortical axis. Ann N Y Acad Sci. 1995;771:115-30.

56. Koolhaas JM, de Boer SF, Coppens CM, Buwalda B. Neuroendocrinology of coping styles: towards understanding the biology of individual variation. Front Neuroendocrinol. 2010;31(3):307-21.

57. Koolhaas JM, Korte SM, De Boer SF, et al. Coping styles in animals: current status in behavior and stress-physiology. Neurosci Biobehav Rev. 1999;23(7):925-35.

58. Levin BE. Metabolic imprinting on genetically predisposed neural circuits perpetuates obesity. Nutrition. 2000;16(10):909-15.

59. - Boersma GJ, Benthem L, van Dijk G, Scheurink AJ: Individual variation in the (patho)physiology of energy balance. Physiol Behav 2011, 103(1):89-97. This stresses the importance of individual differences in vulnerability and resilience, and how these differences also should be taken into consideration in prevention and treatment of disease.

60. Boersma G, Benthem L, van Dijk G, Steimer TJ, Scheurink AJ. Pharmacological treatment of hyperinsulineamia in rats depends on coping style. Eur J Pharmacol. 2011;654(1):122-7.

61. Grillo CA, Piroli GG, Hendry RM, Reagan LP. Insulin-stimulated translocation of GLUT4 to the plasma membrane in rat hippocampus is PI3-kinase dependent. Brain Res. 2009;1296:35-45.

62. Masuzaki H, Paterson J, Shinyama H, et al. A transgenic model of visceral obesity and the metabolic syndrome. Science. 2001;294 (5549):2166-70.

63. Cowley MA, Smart JL, Rubinstein M, et al. Leptin activates anorexigenic POMC neurons through a neural network in the arcuate nucleus. Nature. 2001;411(6836):480-4.

64. Bi S, Scott KA, Kopin AS, Moran TH. Differential roles for cholecystokinin A receptors in energy balance in rats and mice. Endocrinology. 2004;145(8):3873-80.

65. Chua Jr SC, Chung WK, Wupeng XS, et al. Phenotypes of mouse diabetes and rat fatty due to mutations in the OB (leptin) receptor. Science. 1996;271(5251):994-6.

66. Clark KJ, Boczek NJ, Ekker SC. Stressing zebrafish for behavioral genetics. Rev Neurosci. 2011;22(1):49-62.

67. Norton WH, Stumpenhorst K, Faus-Kessler T, et al. Modulation of Fgfrla signaling in zebrafish reveals a genetic basis for the aggression-boldness syndrome. J Neurosci. 2011;31(39):13796807.

68. Pavlidis M, Sundvik M, Chen YC, Panula P. Adaptive changes in zebrafish brain in dominant-subordinate behavioral context. Behav Brain Res. 2011;225(2):529-37.

69. Manuck SB, Kaplan JR, Adams MR, Clarkson TB. Effects of stress and the sympathetic nervous system on coronary artery atherosclerosis in the cynomolgus macaque. Am Heart $\mathrm{J}$. 1988;116(1 Pt 2):328-33.

70. Jayo JM, Shively CA, Kaplan JR, Manuck SB. Effects of exercise and stress on body fat distribution in male cynomolgus monkeys. Int J Obes Relat Metab Disord. 1993;17(10):597-604.

71. Shively CA, Register TC, Clarkson TB. Social stress, visceral obesity, and coronary artery atherosclerosis in female primates. Obesity (Silver Spring). 2009;17(8):1513-20.

72. Shively CA, Register TC, Clarkson TB. Social stress, visceral obesity, and coronary artery atherosclerosis: product of a primate adaptation. Am J Primatol. 2009;71(9):742-51.

73. Arce M, Michopoulos V, Shepard KN, Ha QC, Wilson ME. Diet choice, cortisol reactivity, and emotional feeding in socially housed rhesus monkeys. Physiol Behav. 2010;101(4):446-55.

74. Christiansen AM, Dekloet AD, Ulrich-Lai YM, Herman JP. "Snacking" causes long term attenuation of HPA axis stress responses and enhancement of brain FosB/deltaFosB expression in rats. Physiol Behav. 2011;103(1):111-6.

75. • Ulrich-Lai YM, Christiansen AM, Ostrander MM, et al: Pleasurable behaviors reduce stress via brain reward pathways. Proc Natl Acad Sci U S A 2010, 107(47):20529-20534. This is a study suggesting that access to palatable food and drink can dampen the HPA axis response to stress.

76. Blanchard DC, Spencer RL, Weiss SM, Blanchard RJ, McEwen B, Sakai RR. Visible burrow system as a model of chronic social stress: behavioral and neuroendocrine correlates. Psychoneuroendocrinology. 1995;20(2):117-34.

77. Tamashiro KL, Nguyen MM, Fujikawa T, et al. Metabolic and endocrine consequences of social stress in a visible burrow system. Physiol Behav. 2004;80(5):683-93.

78. Nguyen MM, Tamashiro KL, Melhorn SJ, Ma LY, Gardner SR, Sakai RR. Androgenic influences on behavior, body weight, and body composition in a model of chronic social stress. Endocrinology. 2007;148(12):6145-56.

79. Hardy MP, Sottas CM, Ge R, et al. Trends of reproductive hormones in male rats during psychosocial stress: role of glucocorticoid metabolism in behavioral dominance. Biol Reprod. 2002;67 (6): $1750-5$.

80. Tamashiro KL, Nguyen MM, Ostrander MM, et al. Social stress and recovery: implications for body weight and body composition. Am J Physiol Regul Integr Comp Physiol. 2007;293(5):R1864-74.

81. Tamashiro KL, Hegeman MA, Sakai RR. Chronic social stress in a changing dietary environment. Physiol Behav. 2006;89 (4):536-42.

82. Yamamoto K, Irie M, Sakamoto Y, Ohmori S, Yoshinari M. The relationship between IMPS-measured stress score and biomedical parameters regarding health status among public school workers. J Physiol Anthropol. 2007;26(2):149-58.

83. - Melhorn SJ, Krause EG, Scott KA, et al: Meal patterns and hypothalamic NPY expression during chronic social stress and recovery. Am J Physiol Regul Integr Comp Physiol 2010, 299(3): R813-822. This is a study of feeding behavior and meal patterns of SUB rats during and following chronic social stress exposure.

84. Fabry P, Tepperman J. Meal frequency-a possible factor in human pathology. Am J Clin Nutr. 1970;23(8):1059-68.

85. Wheeler J, Martin R, Lin D, Yakubu F, Hill JO. Weight cycling in female rats subjected to varying meal patterns. Am J Physiol. 1990;258(1 Pt 2):R124-9. 
86. Chapelot D, Marmonier C, Aubert R, et al. Consequence of omitting or adding a meal in man on body composition, food intake, and metabolism. Obesity (Silver Spring). 2006;14(2):215-27.

87. Rybkin II, Zhou Y, Volaufova J, Smagin GN, Ryan DH, Harris RB. Effect of restraint stress on food intake and body weight is determined by time of day. Am J Physiol. 1997;273(5 Pt 2):R1612-22.

88. Arble DM, Bass J, Laposky AD, Vitaterna MH, Turek FW. Circadian timing of food intake contributes to weight gain. Obesity (Silver Spring). 2009;17(11):2100-2.
89. Inui A, Kitaoka H, Majima M, et al. Effect of the Kobe earthquake on stress and glycemic control in patients with diabetes mellitus. Arch Intern Med. 1998;158(3):274-8.

90. Goodyear LJ, Kahn BB. Exercise, glucose transport, and insulin sensitivity. Annu Rev Med. 1998;49:235-61.

91. Gathercole LL, Bujalska IJ, Stewart PM, Tomlinson JW. Glucocorticoid modulation of insulin signaling in human subcutaneous adipose tissue. J Clin Endocrinol Metab. 2007;92 (11):4332-9. 